\section{Teaching and training in substi- tutive approaches to animal testing: Commitment of the University of Genoa}

\author{
Anna Maria Bassi \\ Laboratory Analysis and Research in \\ Physiopathology (LARF), Department of \\ Experimental Medicine, University of \\ Genoa, Genoa; Inter-University Center \\ for the Promotion of the 3Rs Principles \\ in Teaching \& Research (Centro 3R), \\ Italy
}

\begin{abstract}
The 21 st century life science requires that scientists become aware of scientific and ethical issues of substitutive approaches to animal testing. For more than 20 years Dr Bassi Team at University of Genoa promotes several activities in Academia on the Replacement of Animal Testing: 2 days training course, lectures within teaching programs, work experience opportunities for graduated or graduating students, stages for Biology, Medicine and Surgery degrees and $\mathrm{PhD}$ courses on human in vitro model disease projects, This effort is now improved by Centro3R activities to increase the number of scientists aware of effective alternatives to classical in vivo approaches, and prevent needless suffering of animals.
\end{abstract}

\section{Introduction}

Up to now, increased clinic evidence has shown the difficult extrapolation of data from animals to humans. So new toxicity testing models based on human biology are required. To respond more effectively to the public's demand for the replacement of animal methods, the 3Rs concept highlights to foster innovative technologies and encourage approaches. To accelerate the process of replacement of animals in biomedical research, education, and regulatory testing, many countries have already established institutions dedicated to the development of alternatives to animal testing. For this aim academic degree programs in Animal Replacement Science have to be established for training the next generation of scientists, ethicists, and policy makers. Education and training are the fundamental commitment of Academia and so in this framework future scientists should be educated, giving them the means and impetus to develop new and appropriate experimental methods. Every researcher should know about relevant alternatives, the scientific limitations of both animal approaches and non-animal ones. In this context the lectures and training are to perform by scientists, regulators. ${ }^{1-5}$

\section{Results}

To address these issues, since 2008, I and my team at Laboratory Analysis and Research in Physiopathology (LARF), at the University of Genoa, have provide theoretical and training courses on the Replacement of Animal Testing. In 2013, the LARF team won the international Lush Prize for Training Category.

Thanks to over thirty years of experience in various fields of pathology and teaching, the LARF staff is able to offer their knowledge and expertise in all aspects of in vitro technology. To date, LARF have hosted 8 editions of Basic and 5 of Advanced courses. The courses are organized over 2-days and are opened to a maximum of 24 participants, including experts in in vitro methods, as well as undergraduates. Low registration fees to permit even young graduates to participate and participants come from all over Italy.

These Courses are not funded from Academia, but only voluntary donations by some animal protection associations. It is to emphasize that leading Companies in in vitro areas contribute as sponsor by sending their specialists for talks and supervising the training modules focused on their top technologies or methods, and this is done with their own free-will. Thanks to this relevant support, each edition is unique in providing regular updates on main relevant topics of innovative in vitro models and technologies, implementation of current regulatory issues, adverse outcome pathway analytical construct, and so on. The theoretical part is combined with intensive sessions of hands-on experience within practical training modules given by specialists from the academic world and leading technology companies. The topics of these courses are focused on supplying basic knowledge, update on innovative in vitro models and technologies, implementation of regulatory issues, adverse outcome pathway analytical construct, and so on. Furthermore, the experts offer hands-on experience to each participant in specific practical training modules. A panel discussion among experts and trainees during the hands-on sessions and in the final roundtable contributed to creating a scientific network on alternative methods.
Correspondence: Anna Maria Bassi, Laboratory Analysis and Research in Physiopathology (LARF), Department of Experimental Medicine, University of Genoa, Genoa, Italy.

E-mail: anna.maria.bassi@unige.it

Key words: 2D, 3D in vitro model; in silico methods; training; teaching.

Conference presentation: this paper was presented at the Second Centro 3R Annual Meeting - 3Rs in Italian Universities, 2019 , June 20-21, University of Genoa, Italy.

Received for publication: 28 October 2019. Accepted for publication: 6 November 2019 .

This work is licensed under a Creative Commons Attribution NonCommercial 4.0 License (CC BY-NC 4.0).

(C) Copyright: the Author(s), 2019

Licensee PAGEPress, Italy

Biomedical Science and Engineering 2019; 3(s2):81 doi:10.4081/bse.2019.81

The evaluation questionnaires result in a high level of satisfaction by all participants, who appreciate the guarantee of being able to use in vitro models and of getting updates, and more than often, request the scheduling of new advanced courses to improve existing expertise on alternative methods confirming their very positive learning outcomes.

Moreover, we promote and organize several training activities in Academia. Within the core curricula of my teaching programs, I give lectures, offer "stages", work experience opportunities, for graduated or graduating students of several Courses. Several graduating and $\mathrm{PhD}$ students elaborate their degree thesis on in vitro models and every year $20 \mathrm{~h}$ training modules on in vitro toxicology are performed for graduating students in Biology, Medicine and Surgery, as for graduates, as a voluntary stage. It is to underlined that within the Medicine and Surgery Degree, we offer 6 hours of lectures within an optional course, on "in vitro Alternative Models for Personalized Medicine", and recently 1 student/year has working an experimental thesis on a human in vitro model disease project, for a total of 2 years.

In addition, for each edition of 2 nd level Master Courses on the REACH guidelines, I am engaged in 4-hour lessons on Innovative in vitro Models for Risk Prediction; plus 2 hours of practical activity on skin or eye reconstructed human tissues, as required for irritation tests according to respective $\mathrm{OECD}$ regulations. 


\section{Conclusions}

Dissemination of 3R-knowledge ensures best possible practice for a predictive and reliable toxicology, by performing and optimizing $2 \mathrm{D} / 3 \mathrm{D}$ in vitro models based on human cells to evaluate the health hazard. At present, there is a strong commitment of both researchers and companies to perform advanced human-specific models. Establishing training programs around the world makes a huge difference to progress.

\section{References}

1. Scanarotti C, Rovida C, Penco S, et al. Giving meaning to alternative methods to animal testing. ALTEX 2018;35:2567.

2. Scanarotti C, Rovida C, Penco S, et al. Alternative approach to animal testing and cell cultures, according to European laws. ALTEX 2017;34:441-2.

3. Sambuy Y, Bassi AM, Scanarotti C, Caloni F. Meeting report: From Cells to QSAR: an alternative predictive models in toxicology. ALTEX 2017;34:167-71.

4. Bassi AM. 2013 Lush Training Prize: Anna Maria Bassi's Research Team, Laboratory of Analysis and Research of Physiopathology (LARF), Department of Experimental Medicine, University of Genova, Italy. Alternatives to laboratory animals ATLA 2014;42:407-8.

5. Bassi AM, Scanarotti C, Vernazza S, et al. Commitment of Italian academic LARF-DIMES for teaching and training in alternative approach to animal testing. ALTEX Proceed 2016;5:18. 